for those who have not been initiated into ophthalmology. It is extraordinary how little even educated people know about their eyes : many do not even know the difference between an oculist and an optician. There was a need for a book of this sort, in which the writing is easy and the style at times colloquial, addressed to the great mass of the population.

Certain widely spread erroneous ideas about eye work being harmful to the eye, glasses tending to weaken the sight and that it is possible to take the eye out, scrape it and put it back again. are demolished, and the reader is conducted up the zoological staircase from the reaction of the amoeba to light to vision in the human species.

In discussing myopia the authors say that we know of no means of checking the growth of the child, but if they will refer to Nicholas Nickleby they will find that Mr. and Mrs. Crummles put the infant phenomenon on to an unlimited allowance of gin and water from infancy in order to keep her small. Perhaps this idea needs to be demolished with the others.

Many interesting facts emerge from these pages. Bulls are colour blind and it is not the red cloak that irritates them, but more probably the movement. Bees do not see red; wasps are not mentioned, but the small urchin who pokes a stick into a wasp's nest might disagree as far as wasps are concerned. Seals are highly astigmatic. We congratulate the authors most heartily. The chapters are all good, especially those on colour vision; vitamins and vision; things that may go wrong with the mechanism of seeing; things which may affect the function of the eyes, apart from disease and injury; what the blind can do and how they can be taught.

All those of Victorian status will appreciate the reference to the use of a stereoscope on Sunday afternoons combining amusement with latent instruction.

With regard to the limerick on page 80 we do not claim to be a Hampshire $\mathrm{Hog}$, but would suggest that the village of Cosham in that county would rhyme better with "wash 'em" than East Bosham. We were under the impression that the latter was pronounced "Boseham".

\title{
CORRESPONDENCE
}

\section{MYOPIA AND PSEUDO-MYOPIA}

To the Editors of THE BRITISH JouRnal of OPHTHALMOLOGY.

DEAR SIRS,-I desire to support Mr. Lavery in what he has said in your last issue on "Myopia and Pseudo-myopia " by Mr. Spencer Walker and I should like to go a step further. 
His letter has particularly brought home to me the case of a young man who came to me the other day complaining that he had been rejected in the visual examination for the Master Mariner's Certificate. When he first consulted me a few years ago he was accompanied by his father. I explained to him that though his son would probably pass his entrance examination I was afraid that he would not pass his final because his myopia would most likely have increased by that time.

Now my point is why should such a healthy young man with excellent colour vision and with only a slight amount of myopia, be lost to the services of the Mercantile Marine or even to the Navy, but be acceptable to the land forces. It seems to be perfectly correct for an Admiral or a Sea Captain to view a ship in the offing by means of a pair of binoculars but incorrect for him to do the same thing with a pair of glasses poised on his nose.

Our Faculty of Ophthalmology should endeavour to educate the powers that be to a more sane and reasonable outlook on these matters. Many a worthy Son of the Sea whose ancestors have played their part in making England great has been cast aside as worthless because he had half a dioptre of myopia.

I think the whole subject of myopia merits careful and serious consideration. Is it wise for the M.O.H. to insist on the refractionist getting $6 / 6$ or $6 / 5$ vision with minus glasses or would the pupil have been better treated if his $6 / 9$ vision had been untouched and plus glasses with base in prisms been prescribed to assist his accommodation and convergence?

Yours faithfully,

Francis E. PRESTON

44, QUEEN ANN STREeT, W.1

25th February, 1947

\section{REMOVAL OF THE WRONG EYE}

To the Editors of THE BRITISH JOURNAL OF OPHTHALMOLOGY.

DEAR SIRS, - It was with great interest that I read, in the January issue of the Journal, the interesting article by Dr. H. M. Traquair, concerning the removal of the wrong eye. May I offer a safe and simple method to the profession to avoid this mistake, and may I be allowed to correct a linguistic misinterpretation in this article?

The misinterpretation was due to the translation of the "Soll" in Elschnig's quotation. The "Soll" is equivalent to the Latin "Dicitur" and does not mean that this case has actually occurred; it means that it was said (by someone) that the case has (somewhere) 